\title{
Examining Higher Education Instructor Perceptions of Roles and Competencies in Online Teaching
}

\author{
Florence Martin \\ University of North Carolina Charlotte, USA \\ Swapna Kumar \\ University of Florida, USA \\ Liane She \\ University of North Carolina Charlotte, USA
}

\begin{abstract}
Online instructors adopt various roles and perform various competencies in the design and delivery of online courses. In this study, online instructor roles are categorized into eight types including Subject Matter Expert, Course Designer and Developer, Course Facilitator, Course Manager, Advisor/Mentor, Assessor/Evaluator, Technology Expert, and Lifelong Learner. Through surveybased research with 141 online instructors, this study examines competencies that online instructors perform based on various roles. When rating competencies, overall categorical means for all the roles were rated above 4.00, which showed that they used all these roles. The highest rated items and lowest rated items are discussed in addition to the connection between research and practice in online teaching. Online instructors who participate in training and who collaborate with instructional designers rated the frequency with which they perform the competencies to be higher. This study has implications for online instructors, instructional designers, and administrators who design and deliver online learning and offer professional development for online instructors.
\end{abstract}

Keywords: Online teaching, online instructors, instructor roles, instructor competencies, online higher education

Martin, F., Kumar, S., \& She, L. (2021). Examining higher education instructor perceptions of roles and competencies in online teaching. Online Learning, 25(4), 267-295.

DOI: $10.24059 /$ olj.v25i4.2570 
The number of online courses in higher education in the United States has increased over the last two decades, resulting in a 5.6\% increase of distance education students and $6.4 \%$ decrease of on-campus students (Seaman et al., 2018). This has resulted in a need for more instructors to teach in the online environment (Legon et al., 2020). Teaching in the online environment involves a shift in instructors' roles and teaching practices as they adapt to the affordances and possibilities of online environments (Baran et al., 2011; Bennet \& Lockyer, 2004; Wiesenberg \& Stacey, 2008). Instructors must teach in a student-centered manner and work in high-interaction environments (Beck \& Ferdig, 2008). Online instructors require different competencies than face-to-face instructors, and this has resulted in a need for professional development for online instructors (Borup \& Evmenova, 2019; Mohr \& Shelton, 2017). Spector and De la Teja (2001) and Richey et al. (2001) describe competence or competency as the ability to effectively perform a job task or activity to meet the requirements of the job, while a role is defined as "the function assumed or part played by a person or thing in a particular situation" (Peters et al., 2017, p.1).

Over the last two decades, researchers have studied the functions of online teaching and the competencies needed by instructors when teaching online (Baran et al., 2011; Berge, 2009; Coppola et al., 2002; Dennis et al., 2004). The International Board of Standards for Training, Performance, and Instruction (IBSTPI) has also created a competency development model (Klein et al., 2004), where learning and development competencies are categorized by roles and performance statements. IBSTPI has competency sets for instructors, online learners, instructional designers, training managers, and evaluators. In the IBSPI competency development model, competencies for each role are identified by domains. Each competency also includes detailed performance statements. For instructor competencies, domains include professional foundations, planning and preparation, instructional methods and strategies, assessment and evaluation, and management. Alvarez et al. (2009) used a model of identifying roles, specific competencies, and tasks for university instructors. Figure 1 includes this visual representation of defining roles, identifying competencies by roles, and describing tasks by competencies and roles.

Figure 1

Roles, Competencies, and Tasks for Instructors

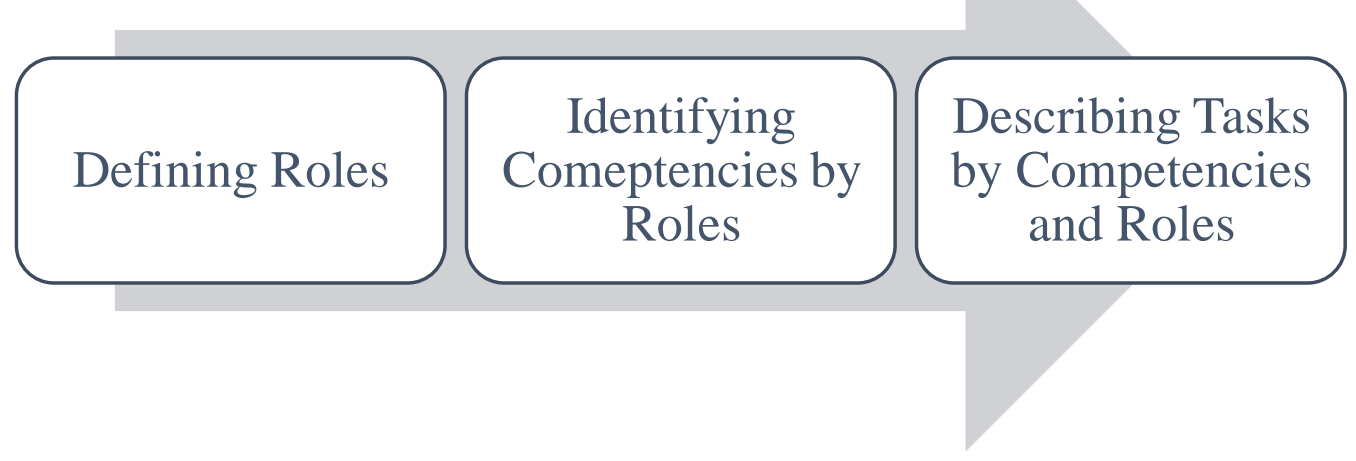

Adapted from Alvarez et al. (2009). University teacher roles and competencies in online learning environments. A theoretical analysis of teaching and learning practices. European Journal of Teacher Education, $32,323$. 
Given the dynamic increase in online education (Seaman et al., 2018), developments in online communication technologies, and the need for online instructor professional development in the last decade, it is important to identify the necessary competencies needed for online instructors. This study examined the competencies of online instructors in higher education and whether instructors' completion of required training or collaboration with instructional designers resulted in increased online learning competencies. The results of our research will be valuable to instructors and researchers in online education, professionals and administrators working with online instructors, and institutions of higher education engaged in professional development for online teaching.

\section{Online Instructional Functions and Roles}

Several studies have examined competencies for online instructors focused on the functions of online teaching (Berge, 2009; Coppola et al., 2002; Dennis et al., 2004; Varvel, 2007). Coppola et al. (2002) define online teaching functions as cognitive, affective, and managerial. Cognitive relates to helping students process and store information efficiently; affective relates to creating a deeper connection with students and allowing them to show their emotions, and managerial relates to keeping the classroom structured and organized as well as to monitoring students. In line with the affective function, it is paramount for the instructor to accommodate individual needs, encourage self-directed learning, undertake a review of the teaching and learning process, and offer multiple perspectives (Lee, 2011). Similarly, Berge (1995) stated that the pedagogical function consists of facilitating discussions, the social function consists of encouraging and promoting collaborative work, the managerial function shows that instructors organize and describe the logistics of discussions, and the technical function provides a transparent technology environment to the learners. Building on these studies, Baran et al. (2011) recommended competencies for pedagogical, social, managerial, and technical functions.

On the other hand, several studies have also examined competencies for online instructors based on their roles (Aydin, 2005; Bawane \& Spector, 2009; Goodyear et al., 2001; Martin et al., 2019a; Thach \& Murphy, 1995; Williams, 2003). Bawane and Spector (2009) categorized online instructor roles into eight types: professional, pedagogical, social facilitator, evaluator, administrator, technologist, advisor/counselor, and researcher roles. The results of Bawane and Spector's (2009) study, in which instructors with at least two years of experience in online teaching participated, indicated that the instructor's foremost role is pedagogical. They also concluded that prior to teaching online, instructors need to be provided with competencies and roles required for successful online teaching. In their study with award-winning online instructors, Martin et al. (2019a) identified online instructor roles as aligned with various parts of the teaching process, such as course design, facilitation, and assessment, and identifying roles such as facilitator, course designer, content manager, subject matter expert, and mentor.

Table 1 lists the various online instructor roles and functions found in the literature, along with a description of the research method and participants.

\section{Table 1}

\section{Online Instructor Functions and Roles}

\begin{tabular}{lll}
\hline Online Instructor Functions/ Roles & Researchers & $\begin{array}{l}\text { Research Method and } \\
\text { Participants }\end{array}$ \\
\hline Instructor, Instructional Designer, Technology Expert, & Thach and Murphy (1995) & $\begin{array}{l}\text { Delphi Survey Methodology } \\
\text { (51 first round, 36 second } \\
\text { Technician, Administrator, Site Facilitator, Editor, }\end{array}$ \\
Librarian, Evaluation Specialist, Graphic Designer & & round distance educators)
\end{tabular}


Process facilitator, advisor/counselor, assessor, researcher, content facilitator, technologist, designer, and manager/administrator

Cognitive, affective, and managerial.

Administrative manager, instructor/facilitator, instructional designer, trainer, leader/change agent, technology expert, graphic designer, media publisher/editor, technician, support staff, librarian, evaluation specialist, site facilitator/proctor.

Pedagogical, communicational, discipline, expertise, and technological.

Content expert, process facilitator, instructional designer, advisor/counselor, technologist, assessor, material producer, administrator

Administrative, personal, technological, instructional design, pedagogical, assessment, social.

Pedagogical, social, managerial, technical.

Professional, pedagogical, social, evaluator, administrator, technologist, advisor/counselor, and researcher.

Pedagogical, social, managerial, and technical.

Pedagogical, managerial, technical, affective, and differentiating.

Pedagogical, social, evaluator, administrator/manager, technologist, advisor/counselor, personal, researcher Instructional design, facilitating learning, learning assessment, technology use, administration management, content expertise, research development

Course designer and organizer, discussion facilitator, social supporter, technology facilitator, and assessment designer

Facilitator, Course Designer, Content Manager, Subject Matter Expert, and Mentor
Goodyear et al. (2001) Report

Coppola et al. (2002) Interviews (20 faculty)

Williams (2003)

Delphi Questionnaire (15

distance education mentors)
Dennis et al. (2004) Observations

Aydin (2005) S Survey (53 mentors)

Varvel (2007) Literature review

Berge (2009) Literature review

Bawane and Spector Survey (30 teacher (2009) educators)

Baran et al. (2009)

Literature review

Lee (2011)

Survey (248 students)

Muñoz Carril et al. (2013) Literature review, survey

(166 instructors)

Chang et al. (2014)

Survey (106 instructors)

Hung \& Chou (2015)

Survey (750 students)

Martin et al. (2019a)

Interviews (8 awardwinning instructors)

Based on the literature review, this study categorized roles as Subject Matter Expert, Course Designer and Developer, Course Facilitator, Course Manager, Advisor/Mentor, Assessor/Evaluator, Technology Expert, and Lifelong Learner. 


\section{Subject Matter Expert}

Instructors are primarily seen as knowledge experts of the subjects they teach. In the Chang et al. (2014) study, online instructors viewed content expertise as the most important and frequently used role in online teaching. Being a content expert was one of the top two roles identified in Aydin's (2005) study as well. In other literature, content expertise is either explicitly identified or presumed in the pedagogical role of online instructors (Goodyear et al., 2001; Lee, 2011). Additionally, identifying appropriate resources representative of the content and designing activities to enhance student engagement and active learning are key to the instructor's role in online courses. This ensures that the course is enriching for the students and helps them take control of their learning (Caplan \& Graham, 2004; Dennis et al., 2004). Likewise, course content must be adapted appropriately to provide students with constructive knowledge that is not solely textbook based (Conrad, 2004). In addition to knowledge of related subjects, online instructors are expected to be culturally neutral regarding course content and provide clear directions in multicultural online learning environments to provide effective learning opportunities for students (Lee, 2011). In online courses, the instructor's ability to use a variety of sources appears to be helpful and accessible to students. In contexts where students oversee their own learning experience and connect new knowledge with previous or current life experiences, instructors must keep in mind that activities should be geared towards the learner's active participation by being task or problem-centered (Gibbons \& Wentworth, 2001).

\section{Course Designer or Developer}

The role of the instructor as course developer or instructional designer was identified in much of the literature (Aydin, 2005; Goodyear et al., 2001; Hung \& Chou, 2015; Williams, 2003; Varvel, 2007). In an online course, instructors must identify learning goals and define smaller units and learning objectives, aligning activities with unit and course objectives for the desired learning outcomes. The course designer may be considered as a project manager, editor, and web developer, as they ensure that the alignment between the course layout and the selected course materials are properly and clearly linked (Caplan \& Graham, 2004). It is paramount to structure to select relevant activities that correspond to course content as well as to design effective assessments (Yuksel, 2009). Inclusive design that uses interactive and globally accessible materials as well as multimedia resources with various formats allows students to engage with course content in various forms (Caplan \& Graham, 2004). Course design also includes planning all aspects of design, including learning activities and communications that will promote interactions among students and between student and instructor (Alvarez et al., 2009). It involves design and planning before, during, and after the course, including course improvement to improve student learning. In addition to designing interactive learning experiences and structuring a course clearly, the regular updating of course materials and sharing of course experiences with colleagues is important (Liu et al., 2005). Liu et al. (2005) state that course designs can also be shared with other colleagues from the same institution to ensure consistency and collaboration among instructors.

\section{Course Facilitator}

In an online environment, instructors must facilitate, interact, and engage rather than lecture, so that the instructor's role shifts from being teacher-centered to student-centered (Beck $\&$ Ferdig, 2008). One of the most important roles of online instructors has thus been described as that of a facilitator (Ryan et al., 2004) or facilitator of the learning process (Aydin, 2005). While Dennis et al. (2004) discussed the role of the online instructor as a content designer as well as a process facilitator, Goodyear et al. (2001) described the process facilitator as implementing 
online activities, especially those involving higher order thinking to support student learning. Hung and Chou (2015) define the instructor's role more specifically to be one of discussion facilitator in this context. According to Barber and King (2016), the instructor is required to facilitate, guide, and collaborate to engage students and increase their curiosity towards learning and the use of technology. When students first log in to the class, instructors must guide them efficiently through the course, welcome them, help them locate course resources, and clarify what the course will entail. This may be done through a variety of actions such as a welcome video or email and through the syllabus (Caplan \& Graham, 2004).

Martin et al. (2018) summarized several facilitation strategies that instructors can use in an online course to enhance learning, engagement, instructor presence, and instructor connection. Their classification of facilitation strategies shows that instructor facilitation can support managerial, pedagogical, social, and technical functions. Providing timely feedback and responses to student questions were the two facilitation strategies highly rated as being helpful for learning, engagement, establishing instructor presence, and connection. Additionally, facilitators should accommodate the individual needs of students, help them to be self-directed, and expose them to multiple perspectives (Lee, 2011).

A facilitator can also be seen as the online community builder within the classroom (Berry, 2017; Roehm \& Bonnel, 2009). To increase learners' engagement throughout the course, the online instructor also fosters relationships within the course. This develops a sense of community among learners (Maor, 2003). Facilitating the course can involve creating collaborative activities and discussions that allow students to interact and share their experiences. The instructor's role shifts from traditional lecturer to facilitator and guide for those assignments (Roehm \& Bonnel, 2009). However, both student-student collaboration and instructor-student communication and dialogues must exist in an online course for active participation and cognitive presence (Dennen, 2011; Dixson et al., 2006). A course facilitator ensures clarity, understanding, and guidance among students, and monitors their progress throughout the course.

\section{Course Manager}

Online instructors are also course managers, or administrative managers, described in the literature as having managerial functions, administering an online course, or managing the learning (Aydin, 2005; Bawane \& Spector, 2009; Berge, 2009; Chang et al., 2014; Coppola et al., 2002; Martin et al., 2019a; Williams, 2003). In addition to managing an online course in a learning management system by administering course policies and grades and ensuring adherence to departmental and college-level policies, instructors also manage their own course rules and structure. They are expected to remain patient and clear, manage their time, manage communication and conflict within a course, and not overload students with excessive course content and activities. As such, course managers must show effective leadership qualities and be knowledgeable of the course structure and content so they can better assist learners (Bawane \& Spector, 2009).

\section{Advisor and Mentor}

Online instructors are also advisors and mentors (Martin et al., 2019a). Goodyear et al. (2001) describe this role as a consultant and counselor who advises students, while Dennis et al. (2004) and Bawane and Spector (2009) define it as an advisor and counselor, and Aydin (2005) as an online mentor. While advising is considered as a transactional process where students are advised about courses (e.g., course registration), mentoring is considered transformational and usually involves collaborative, connected, and reciprocal relationships (Johnson, 2007) during research and dissertation. Additionally, the role of the instructor is to inspire students to develop 
reflective thinking and create a quality learning experience (Maor, 2003). This is captured in the affective role, where instructors who are social, provide off-task activities, develop and support learning communities, give affective support, and establish rapport have a direct impact on students' cognitive learning in online environments (Lee, 2011). Liu et al. (2005) also describe this role as that of a profession-inspirer, as an advisor who can point learners to professional organizations and promote professional dialogue related to their personal experiences in the discipline.

\section{Assessor and Evaluator}

Online instructors are also assessors and evaluators. The term assessment is used to emphasize the focus on learning, and evaluation is used to focus on teaching. Goodyear et al. (2001) describe this role as one where instructors assess student work and provide feedback, while Liu et al. (2005) emphasize the provision of timely, high quality, constructive, and formative feedback for student learning and autonomy. The role of a learning assessor was considered the third most important role of online instructors following content expertise and instructional design by instructors in the Chang et al. (2014)'s study. Dietz-Uhler et al., (2007) recommended that each instructor assess students' knowledge of online learning before the class commences to determine whether students need additional guidance in basic computer and technological knowledge. Additionally, providing students with a self-assessment tool at the end of each module to determine whether the learning outcome was achieved allows them to take control of their learning while evaluating themselves with the instructor's guidance.

In an online course, instructors need to ensure that students' progress through the course and understand the material and provide additional assistance to students not achieving course objectives (Liu et al., 2005). In addition, assessing students also means that they regularly check the course and log in to keep track of assignments, and that they are using the resources provided by the instructor. Additionally, sharing resources with other instructors can also improve quality since instructors can receive feedback and support from other colleagues.

As an evaluator, the instructor collects feedback from students to formatively and summatively evaluate the course during and at the end of the course. They do this by administering course surveys or through discussions in the course. As an evaluator, the instructor also receives feedback from peers and provides feedback to colleagues on online teaching. They also continually evaluate the course by participating in programs such as Quality Matters to evaluate their courses (Martin et al., 2019b).

\section{Technology Expert}

The online instructor is a technology expert. When working in an online environment, the instructor needs technological skills and knowledge to use the learning management system (LMS) and interactive technologies that can facilitate online interactions or receive assistance from instructional designers when necessary (Liu et al. 2005). The instructor needs to have technical capabilities to guide students through technology and make them feel more comfortable (Lee, 2011). The instructor's technical role also presumes that the instructor can effectively use video/audio tools and chat/discussion programs to develop user-friendly courses and resources to benefit learners. For an online instructor, developing course content using technology is the first action performed while teaching, when instructors first engage in e-learning (Muñoz Carril et al., 2013).

\section{Lifelong Learner}

Online instructors are lifelong learners. Participants in the Martin et al. (2019a) study emphasized the need for instructor willingness to learn, experiment, and reflect on their courses, 
especially since technologies and online environments constantly change. According to Dempsey (1992), a reflective practitioner looks back and analyzes teaching practices, imagines change, and explores new teaching practices. Instructors can be scholars who inquire into their teaching strategies, exchange information with other online instructors, attend social events such as conferences, and pursue professional development opportunities. As such, instructors are also considered learning partners (Dempsey, 1992) as they must be able to help students establish reflection and social interactions.

Additionally, instructors are also learners who will learn from their peers' experiences and communities of practice (McGee et al., 2017). Online instructor competencies vary depending on their institutions, on resources provided, and training for new instructors (McGee et al., 2017). In addition to other roles, instructors can potentially be learners, as novice instructors will learn from their peers' experiences and communities of practice. Online instructors can also be researchers (Bawane \& Spector, 2009; Muñoz Carril et al., 2013) or engage in research development (Chang et al., 2014) by analyzing data from their courses that can improve courses and student learning.

\section{Other Roles}

Online instructors can also adopt roles such as the librarian, graphic designer, co-learner, site facilitator and proctor, support staff, leader/change agent, systems expert/consultant (Dennis et al., 2004; Egan \& Akdere, 2005; Thach \& Murphy 1995; Williams, 2003). The instructor must not only serve as guide and collaborator to engage students and increase their curiosity, but also as co-learner regarding new technology tools and features. Relationships within the online course and social interactions from the beginning of the course are paramount to build a sense of learning community. This promotes a sense of community among learners and encourages them to collaborate and develop active learning. In addition to reviewing the literature for competencies by roles, the literature on required training for online instructors and collaboration with instructional designers is reviewed next.

\section{Relationship Between Required Training and Online Instructor Competencies}

Researchers have recommended the need for faculty training focusing on methodologies and facilitation to teach online (Moskal et al., 2015; Vaill \& Testori, 2012). Vang et al. (2020) in a study with community college faculty found that $90 \%$ of instructors had completed the required training and found that when institutions require training, online instructors rate the online readiness competencies higher than those who do not. However, another study with faculty members in a university setting found that most faculty members did not have required training before teaching online (Martin et al., 2019c). Baran and Carrea (2014) proposed a three-tiered professional development model for online teaching. The lower level in their framework focused on teaching and included workshops/showcases, training programs, and one-to-one assistance as various professional development methods for teaching. Research is needed to determine whether required training results in increased online instructor competencies.

\section{Relationship Between Instructional Designer (ID) Collaboration and Online Instructor Competencies}

Researchers have studied the collaboration between instructional designers and faculty members. Richardson et al. (2019) examine the importance of faculty and instructional designer collaboration and conclude that instructional designers act as coaches and facilitators who guide instructors in course design. In another study, Halupa (2019) discusses the collaborative roles of faculty members and instructional designers as content experts and design experts respectively. Chao et al. (2010) in their study found that collaboration was most successful when instructional 
designers have a rapport with faculty members, who were then more likely to implement ID guidelines in the design of their courses. More research is needed to examine whether online instructor collaboration with instructional designers results in increased competencies.

\section{Purpose of This Study and Research Questions}

Of the few empirical studies that have been conducted related to online instructor roles and competencies, some have used interviews and observations in a qualitative approach (Coppola et al., 2002; Dennis et al., 2004; Martin et al., 2019b), and others are survey studies (Lee, 2011; Chang et al., 2014; Hung \& Chou, 2015). Almost all survey studies in the last decade have been conducted with students, except for two large-scale survey studies in Taiwan (Chang et al., 2014) and Spain (Muñoz Carril et al., 2013). Online teaching has evolved, online communication technologies and learning management systems have changed, and competencies have also changed over the years. Therefore, the current competencies of online instructors need to be examined in an ongoing fashion. This study addresses the following research questions:

1. What competencies do online instructors perform for various roles?

2. Are the factors required training and instructional designer collaboration related to increased instructor competencies for online teaching?

\section{Methods}

This section documents the details of the survey-based research, including participants, creation of the instrument, data collection, and analysis.

\section{Participants}

The sample consisted of online instructors across the United States. The researchers recruited online instructors through the Association of Educational Communications and Technology (AECT) email list and through a distance education email list at a Southeastern University. A total of 148 online instructors completed the electronic survey, of which 141 valid responses were received. The respondents from AECT and the southeastern university were not statistically significantly different from each other with respect to gender, $\chi^{2}(d f=4)=5.70, p=$ .22 , rank, $\chi_{2}(d f=4)=6.70, p=.15$, years of teaching online $\chi_{2}(d f=6)=2.45, p=.87$, and learning environment taught $\chi_{2}(d f=4)=1.45, p=.83$. As a result, all respondents were grouped together for further analysis. Table 2 below provides the demographic and experience details of the respondents.

\section{Table 2}

\begin{tabular}{|c|c|c|c|}
\hline $\begin{array}{l}\text { Demographic } \\
\text { Variable }\end{array}$ & Demographic Details & Frequency & Percentage \\
\hline \multirow[t]{3}{*}{ Gender } & Male & 41 & 29.1 \\
\hline & Female & 95 & 67.4 \\
\hline & Other & 4 & 2.8 \\
\hline \multirow[t]{6}{*}{ Rank } & Adjunct Instructor & 27 & 19.1 \\
\hline & Instructor or Lecturer & 39 & 27.7 \\
\hline & Assistant Professor & 21 & 14.9 \\
\hline & Associate Professor & 24 & 17.0 \\
\hline & Professor & 16 & 11.3 \\
\hline & Other & 11 & 7.8 \\
\hline \multirow{2}{*}{$\begin{array}{l}\text { Primary Learning } \\
\text { Environment Taught }\end{array}$} & Blended or Hybrid & 35 & 24.8 \\
\hline & Online Asynchronous & 65 & 46.1 \\
\hline
\end{tabular}




\begin{tabular}{|c|c|c|c|}
\hline & Online Synchronous & 21 & 12.1 \\
\hline & Other & 17 & 14.9 \\
\hline \multirow[t]{3}{*}{ Teaching Level } & Undergraduate & 75 & 53.2 \\
\hline & Graduate & 47 & 33.3 \\
\hline & Other & 16 & 11.3 \\
\hline \multirow[t]{3}{*}{ Teaching Institution } & 4 year & 116 & 82.3 \\
\hline & 2 year & 9 & 6.4 \\
\hline & Other & 14 & 10.0 \\
\hline \multirow[t]{9}{*}{ Academic Discipline } & Arts & 12 & 8.5 \\
\hline & Sciences & 14 & 9.9 \\
\hline & Business & 7 & 5.0 \\
\hline & Computer Science & 6 & 4.3 \\
\hline & Education & 57 & 40.4 \\
\hline & Engineering & 6 & 4.3 \\
\hline & Health Sciences & 12 & 8.5 \\
\hline & Law & 1 & 0.7 \\
\hline & Other & 25 & 17.7 \\
\hline \multirow[t]{5}{*}{ Expertise } & Novice & 6 & 4.3 \\
\hline & Advanced Beginner & 17 & 12.1 \\
\hline & Intermediate & 35 & 24.8 \\
\hline & Proficient & 55 & 39.0 \\
\hline & Expert & 27 & 19.1 \\
\hline \multirow{4}{*}{$\begin{array}{l}\text { Online Teaching } \\
\text { Experience }\end{array}$} & $1-5$ years & 66 & 46.8 \\
\hline & 6-10 years & 25 & 17.7 \\
\hline & $11-15$ years & 21 & 14.9 \\
\hline & More than 15 & 28 & 19.9 \\
\hline \multirow[t]{4}{*}{ Online Courses Taught } & $1-5$ & 54 & 38.3 \\
\hline & $6-10$ & 30 & 21.3 \\
\hline & $11-15$ & 19 & 13.5 \\
\hline & More than 15 & 36 & 25.5 \\
\hline \multirow{2}{*}{$\begin{array}{l}\text { Taught online before } \\
\text { COVID }\end{array}$} & Yes & 120 & 85.1 \\
\hline & No & 20 & 14.2 \\
\hline \multirow[t]{3}{*}{ Collaborated with ID } & Yes & 89 & 63.1 \\
\hline & No & 47 & 33.3 \\
\hline & Not Sure & 4 & 2.8 \\
\hline \multirow[t]{3}{*}{ Training Required } & Yes & 52 & 36.9 \\
\hline & No & 73 & 51.8 \\
\hline & Not Sure & 13 & 9.2 \\
\hline
\end{tabular}

\section{Instrument}

The Online Instructor Roles and Competencies (OIRC) instrument was developed based on an extensive literature review on online instructor competencies for each role and from previous qualitative research (Martin et al., 2019). The prior qualitative study revealed 38 competencies, but additional competencies identified in the literature have been added. Three 
researchers discussed and refined the roles and competencies. The final list of competencies in eight different role categories was then used to create survey items. The organization of the survey was modeled on the competencies categorized by roles of the International Board of Standards for Training, Performance, and Instruction (IBSTPI) and Alvarez et al. (2009) framework. Using IBSTPI and Alvarez et al. (2009) as the guiding framework in the survey (see Appendix A), roles and competencies for online instructors were organized.

Following its creation, the survey draft underwent expert review. Five experts reviewed the draft instrument and provided feedback on content validity, construct validity, and face validity. While three of the expert reviewers were online learning experts, two of them were research methodologists. Sample comments from the experts included "This would seem like a course facilitator, rather than technology expert," "How do you quantify this?" and "Are these different competencies?" The final list included 58 competencies under eight different roles: Subject Matter Expert, Course Designer \& Developer, Course Facilitator, Course Manager, Advisor/Mentor, Assessor/Evaluator, Technology Expert, and Lifelong Learner. Respondents were asked to rate competencies based on the frequency they perform the competencies. A 5 point Likert scale item was used: $1=$ Never, 2=Rarely, 3=Sometimes, 4=Often, 5=Always. The Cronbach's alpha was used to check the reliability of the internal consistency for all survey items was .87 . Reliability coefficients greater than .80 are adequate and values greater than .90 are good (Kline, 2016; Nunnally \& Berstein, 1995).

In addition, two open-ended questions and 11 demographic questions were included in the survey. Demographic questions included gender (male, female, transgender, other, do not wish to respond); rank (adjunct instructor, instructor or lecturer, assistant professor, associate professor, professor, other); and teaching-focused questions such as learning environment primarily taught (blended or hybrid, asynchronous online, synchronous online, other); level taught (undergraduate courses, graduate courses, other); type of institution (4-year institution, 2year institution, other); online teaching experience (1-5, 6-10, 11-15, more than 15); academic discipline (arts, sciences, business, computer science, education, engineering, health science, law, medicine, other); expertise (novice, advanced beginner, intermediate, proficient, expert); number of courses taught online (1-5, 6-10, 11-15, more than 15); collaboration with instructional designers (yes, no, not sure); and requirement to attend training to teach online (yes, no, not sure). One open-ended question asked respondents to include roles and competencies that were not included in the instrument. The open-ended question was phrased "Have you ever taken on a role in an online course other than the ones listed?" An option identified as "other" was included at the end of each competency category by role so that additional data could be captured for additional competencies. Appendix A includes the survey.

\section{Data Collection}

Data were collected in Summer 2020. Institutional review board approval was received before the survey was distributed for data collection. Email invitations were distributed along with the link to the electronic survey. The respondents provided online consent before completing the survey. Participation in the survey was voluntary, responses were anonymous, and participants received no incentive for their participation in this electronic survey distributed through SurveyShare, an electronic survey tool used at one researcher's university.

\section{Data Analysis}

A total of 148 responses were captured, of which seven responses had more than onethird of the responses missing. These responses were deleted, which resulted in 141 valid cases. Missing Completely at Random (MCAR) analysis was performed, revealing that among the 141 
valid cases, data were missing at random as Little's (1988) MCAR test was not statistically significant. Missing data were replaced with series mean for the Likert Scale data. To answer the first research question, descriptive statistics and frequencies for various roles and competencies are reported in Table 4. In addition, thematic analysis was used to analyze the few responses to the two open-ended questions. Responses were thematically coded, which led to the emergence of two categories - other competencies and explanations or comments - which are described in the results. To answer the second research question, multivariate analysis of variance (MANOVA) was used to see whether the perceptions of online instructors vary across instructors' experience working with instructional designers and requirement to attend training.

\section{Results}

The results section discusses the various competencies online instructors perform and whether participation in required training or collaborating with an instructional designer made a difference in their competencies.

\section{Online Instructor Competencies}

Respondents were asked to rate the frequency with which each competency was demonstrated. The item was worded as "Please indicate the frequency with which you perform the following competencies in your online courses." Means and Standard Deviations are reported for the competencies categorized by each role as shown in Table 4. All eight roles had a categorical mean above 4.00 which showed that most of these roles were used "often" by online instructors. The lowest frequently rated role was advisor and mentor, which was rated at $\mathrm{M}=4.02$. However, this was still rated above 4.00, which shows that online instructors also served as advisors and mentors.

\section{Table 4}

\section{Descriptive Statistics by Various Online Instructor Roles}

Role Mean

SD

Subject Matter Expert

1 Demonstrate content expertise

2 Stay current with research and theories in the field

Contribute relevant content to course outcomes

Collaborate with instructional designers to develop the course

Ensure that the course content is accurate

$4.64 \quad 0.56$

$4.39 \quad 0.72$

Course Designer and Developer

$6 \quad$ Establish learning objectives

Develop learning activities

Include existing instructional resources (texts, OERs, videos)

4.51

0.67

$2.83 \quad 1.37$

Develop digital learning materials

$4.66 \quad 0.61$

4.21

$\mathbf{0 . 5 0}$

7

Ensure alignment between objectives, content and, assessment

$4.27 \quad 1.13$

Develop a course on the Learning Management System

4.52

1.13
0.85

$4.40 \quad 0.88$

10

Provide consistent course structure

$\begin{array}{ll}4.57 & 0.79\end{array}$

Design intuitive course navigation

4.07 


\section{Course Facilitator}

Create a welcome message (announcement, video)

4.65

0.75

Check in with students frequently

$4.56 \quad 0.68$

Help students develop self-regulated learning skills

$4.02 \quad 0.95$

Host synchronous sessions if applicable

3.66

1.26

Hold online office hours

4.08

1.17

Facilitate online discussions

$4.26 \quad 1.03$

Use active learning strategies to engage learners

$4.41 \quad 0.79$

Provide timely and substantive feedback

$4.49 \quad 0.70$

Foster interaction among learners

$4.34 \quad 0.81$

Interact in a culturally sensitive manner

$4.45 \quad 0.87$

Offer multiple perspectives

4.31

0.84

Encourage student reflection

$4.47 \quad 0.81$

Creating a sense of community amongst students from the same course

$4.24 \quad 0.90$

\section{Course Manager}

$4.30 \quad 0.60$

Monitor learner participation

$4.51 \quad 0.86$

Provide clear instructions to learners

4.65

0.74

Be responsive to individual student needs

$\begin{array}{ll}4.56 & 0.77\end{array}$

Enforce course and institutional policies

$4.53 \quad 0.80$

Resolve potential conflicts among learners

$3.85 \quad 1.10$

Connect students with institutional support services

$3.92 \quad 1.10$

\section{Advisor/Mentor}

Advise learners on their academic development.

Advise learners on their professional development.

Motivate the students to succeed.

$3.58 \quad 1.13$

Guide students to be self-directed and responsible for their course work

$4.41 \quad 0.78$

Guide students to access resources when needed

$4.38 \quad 0.81$

Mentor other colleagues who teach online

$4.46 \quad 0.75$

$3.42 \quad 1.17$

4.020 .72

\section{Assessor/Evaluator}

Use a variety of assessments (quizzes, projects)

$4.53 \quad 0.73$

Align assessment to objectives and activities

$4.60 \quad 0.80$

Establish clear grading criteria for assessments

$4.57 \quad 0.73$

Assess students' work

$4.74 \quad 0.60$

Monitor individual student and group progress

4.50

0.76

Proctor online tests if applicable

$2.64 \quad 1.62$

Continually improve the course

$4.53 \quad 0.80$

Technology Expert

$4.30 \quad 0.62$

Ensure that students are comfortable in the learning environment $\quad 4.22 \quad 4.36$

Orient the students to the online course

$4.36 \quad 0.96$

Use appropriate technology to support learning

$4.42 \quad 0.85$

Provide students with resources for technical help and support

4.27

0.97

\section{Lifelong Learner}

$4.32 \quad 0.83$

Integrate best practices from research into online teaching

$4.46 \quad 0.70$

Engage in professional development on online learning

$4.22 \quad 0.81$

Share and learn from peers about online teaching practices

4.25

0.83

Use data from the online course for continuous improvement

4.23

0.91

Keep pace with the advances in educational technologies

4.16

0.75 
The categorical means for the roles were all above 4.0 and ranged between 4.02 and 4.34, which demonstrated minimal differences (between 0.02 and 0.32) on the overall competencies by the roles, although differences existed in the ratings of individual competencies. The ratings on individual competencies ranged between 2.83 and 4.74, and the highest and least rated individual competencies are discussed below. Of the 58 individual competencies, 48 were rated above 4.0. Five competencies were rated above 4.6: assess students work $(M=4.74)$; ensure that the course content is accurate $(\mathrm{M}=4.66)$; create a welcome message $(\mathrm{M}=4.65)$; provide clear instructions to learners $(\mathrm{M}=4.65)$; and demonstrate content expertise $(\mathrm{M}=4.64)$. Ten competencies were rated below 4.0: proctor online tests if applicable, $(\mathrm{M}=2.64)$; collaborate with instructional designers to develop the course $(M=2.83)$; mentor other colleagues who teach online $(M=3.42)$; advise learners on their professional development $(\mathrm{M}=3.58)$; host synchronous session if applicable $(\mathrm{M}=3.66)$; resolve potential conflicts among learners $(\mathrm{M}=3.85)$; advise learners on their academic development ( $M=3.88)$; ensure accessibility and ADA-compliance $(M=3.92)$; connect students with institutional support services $(M=3.92)$; and develop digital learning materials $(\mathrm{M}=3.98)$.

\section{Other Roles and Competencies}

When asked in an open-ended question whether online instructors have served in any other roles, some additional roles were identified: online student; providing professional development support for other instructors; ensuring the quality of online courses; disciplinarian for academic integrity violation and holding students accountable for their actions; program coordinator; and peer evaluator.

At the end of each role category, participants were asked whether any competencies were not listed. Two competencies were mentioned: a) Subject Matter Expert (SME) collaborations with other content experts and b) setting up individual or 1:1 online meetings with students in a flexible manner, not just online office hours (Course Facilitator role). Eight participants shared that they did all their course design themselves, with one participant stating, "I am responsible for all of it," and another explaining there were no funds for instructional designers. The importance of ADA-compliance and accessibility was highlighted by six participants who stated that often this was the sole responsibility of the instructor. Four participants indicated a lack of control over course content, for instance, that they could not change prescribed learning objectives in an accredited program, or that they did not develop the courses they taught. One participant wrote "As a lecturer, I often just deliver prepared content." Four participants also specified that they did not teach courses where online proctoring was needed.

Differences Based on Training requirement and Collaboration with Instructional Designers

Descriptive statistics are provided for the various roles based on these two significant factors training required and collaboration with instructional designers in Table 5.

Table 5

Descriptive Statistics for Training Required and Instructional Design Collaboration

\begin{tabular}{llllllllll}
\hline & & $\begin{array}{l}\text { Subject } \\
\text { Mater } \\
\text { Expert }\end{array}$ & $\begin{array}{l}\text { Course } \\
\text { Designer } \\
\text { and } \\
\text { Developer }\end{array}$ & $\begin{array}{l}\text { Course } \\
\text { Facilitator }\end{array}$ & $\begin{array}{l}\text { Course } \\
\text { Manager }\end{array}$ & $\begin{array}{l}\text { Advisor/ } \\
\text { Mentor }\end{array}$ & $\begin{array}{l}\text { Assessor/ } \\
\text { Evaluator }\end{array}$ & $\begin{array}{l}\text { Tech } \\
\text { Expert }\end{array}$ & $\begin{array}{l}\text { Lifelong } \\
\text { Learner }\end{array}$ \\
\hline Training & Yes & 4.37 & 4.24 & 4.33 & 4.51 & 4.23 & 4.40 & 4.34 & 4.35 \\
Required & & $(0.52)$ & $(0.71)$ & $(0.73)$ & $(0.67)$ & $(0.77)$ & $(0.65)$ & $(0.92)$ & $(0.66)$ \\
& No & 4.10 & 4.27 & 4.27 & 4.27 & 3.90 & 4.23 & 4.34 & 4.21 \\
& & $(0.45)$ & $(0.67)$ & $(0.54)$ & $(0.67)$ & $(0.68)$ & $(0.61)$ & $(0.72)$ & $(0.64)$ \\
\hline
\end{tabular}




\begin{tabular}{llllllllll}
\hline & & & & & & & & & \\
Instructional & Yes & 4.34 & 4.35 & 4.37 & 4.36 & 4.08 & 4.35 & 4.38 & 4.34 \\
$\begin{array}{l}\text { Designer } \\
\text { Collaboration }\end{array}$ & & $(0.47)$ & $(0.57)$ & $(0.51)$ & $(0.72)$ & $(0.64)$ & $(0.55)$ & $(0.69)$ & $(0.56)$ \\
& No & 3.97 & 4.05 & 4.18 & 4.31 & 3.90 & 4.17 & 4.18 & 4.15 \\
& & $(0.50)$ & $(0.90)$ & $(0.75)$ & $(0.73)$ & $(0.87)$ & $(0.72)$ & $(1.05)$ & $(0.75)$ \\
\hline
\end{tabular}

A multivariate analysis was conducted to examine differences between respondents who were required to take training and those who were not, and those who collaborated with instructional designers and those who did not. Differences were examined for these categories only for those who responded Yes or No. The data for those who responded as unsure were not used. Both of these analyses (training required and not; collaborated with instructional designers and did not) resulted in significant differences $(p<.05)$. Online instructors required to participate in training rated the competencies significantly higher than those who did not have to participate in required training $\mathrm{F}(8,111)=2.658$, Wilk's $\Lambda=0.839$, partial $\eta 2=.16$. Online instructors who collaborated with instructional designers rated the competencies significantly higher than those who did not $\mathrm{F}(8,111)=2.303$ Wilk's $\Lambda=0.858$, partial $\eta 2=.14$.

\section{Discussion}

This section discusses the overall ratings of competencies, and highest and least rated competencies in online teaching. Also discussed are the connections among research and practice, required training, and instructional designer collaboration relationships for online instructor competencies.

\section{Overall Ratings of Competencies}

This study showed no differences in ratings based on roles. In addition, 48 of the 58 total competencies were rated above 4.0, where the Likert scale 4.0 was for "Often" and 5.0 was "Always." This shows the importance of the competencies identified in this study. All competencies in the technology expert and lifelong learner roles were rated above 4.0, while one or two competencies rated low in the other roles. While the list of competencies included both asynchronous and synchronous online teaching, some competencies specifically focused on synchronous teaching and may not be applicable for asynchronous only courses (e.g., host synchronous sessions and proctor tests online).

\section{Highest Rated Competencies}

In this section, we discuss the five top-rated competencies. The five competencies rated the highest by online instructors all related to course content, communication with students, and assessment: assess students' work $(M=4.74)$; need to ensure course content is accurate $(M=4.66)$; create a welcome message $(M=4.65)$; provide clear instructions to learners $(M=4.65)$; and demonstrate content expertise $(\mathrm{M}=4.64)$.

Assess Student Work-Assessor

Assessing student work was the highest-rated competency among the 58 items. This indicates online instructors' involvement in assessing student work in online courses. Martin et al. (2019b) in their study with award-winning online instructors described online instructors as assessors and recommended that online instructors use a variety of assessments, using traditional and authentic assessments and rubrics for assessments in their role as an assessor. 


\section{Ensure Course Content is Accurate-Subject Matter Expert}

Online instructors may, in some situations, only be involved in facilitating a course but not in designing it, while in other situations they are involved both in online course design and delivery. Participants' open-ended comments raised this point in this survey. However, in both instances, online instructors see themselves as subject matter experts who ensure the veracity of the course content and facilitate the delivery of the online course. This is consistent with Chang et al.'s (2014) findings that content expertise was rated highest in e-instructors' perceptions and practice.

\section{Create a Welcome Message-Facilitator}

Online instructors rated welcome messages highly. Research has identified that using a recorded welcome video helps to provide expectations, create a community of learning, and enhance social presence (Khan et al., 2017). The research of Martin et al. (2018) examined facilitation strategies where both course orientation and weekly announcements were included as helpful facilitation strategies. Additionally, weekly announcements were rated highly by both instructors and students in comparison to the course orientation.

\section{Provide Clear Instructions to Learners-Manager}

Providing clear instructions received high ratings. In a face-to-face classroom, instructions can be provided instantly and clarified whereas in an online setting it is important for instructions to be clear ahead of time to avoid confusion. While some students' hesitation to ask for clarification hinders their learning, others might contact the instructor with a number of questions which results in an increased work load for the instructor. When instructions and navigation is unclear it is easy to lose student participation. Rubrics have identified including clear instructions as critical to the success of online students (Quality Matters, 2020).

\section{Demonstrate Content Expertise-Subject Matter Expert}

Demonstrating content expertise was rated high by online instructors as critical for online teaching. This is consistent to the Chang et al. (2014) study on e-instructors' ratings of being content experts. Martin et al. (2019b) when interviewing award-winning online instructors found that the instructors emphasized the importance of creating content for students to achieve mastery. Conrad (2004) also recommended that course content be adapted appropriately to provide students with constructive knowledge and should not solely be textbook based. This shows the importance of online instructors being content experts and focusing on the design of the content for online delivery.

\section{Lowest Rated Competencies}

The ten competencies rated lowest by online instructors were found to be competencies that are not always relevant to all online courses (e.g., synchronous sessions or colleague mentoring). These were: proctor online tests if applicable $(\mathrm{M}=2.64)$; collaborate with instructional designers to develop the course $(\mathrm{M}=2.83)$; mentor other colleagues who teach online ( $M=3.42)$; advise learners on their professional development $(M=3.58)$; host synchronous sessions if applicable $(M=3.66)$; resolve potential conflicts among learners $(M=3.85)$; advise learners on their academic development $(\mathrm{M}=3.88)$; ensure accessibility and ADA-compliance $(\mathrm{M}=3.92)$; connect students with institutional support services $(\mathrm{M}=3.92)$; and develop digital learning materials $(\mathrm{M}=3.98)$. It is important that instructors focus on these competencies even though they may not be consistently performed. 


\section{Proctor Online Tests if Applicable-Assessor/Evaluator}

Proctoring online tests is not a common practice in all online courses and levels (e.g., graduate courses) since this can be expensive and includes a fee at testing centers (Cluskey et al.,2011); therefore, it is understandable that it was rated the lowest. Milone et al. (2017) studied the impact of online proctoring and found that more than half of their study participants mentioned that the use of online proctoring would influence their decision to take another online course which, in turn, could influence instructors' decision to use online proctoring. While academic integrity is important, assessments other than tests is also important (Martin et al., 2019b).

\section{Collaborate with Instructional Designers to Develop the Course-Subject Matter Expert}

While it is good practice to collaborate with instructional designers, the lack of collaboration with instructional designers reported by the respondents could be indicative of the level of support and resources available to online instructors at their institutions. Also, in some cases, faculty members may either not be aware of the presence of instructional designers on their campuses or may not consistently use the support of instructional designers. Many adjunct faculty members may not live close enough to campus to make use of the instructional design support available to them or might teach from course shells that are provided to them.

\section{Mentor Other Colleagues to Teach Online-Mentor}

Among the faculty who responded to this survey, $19 \%$ were adjunct instructors, $28 \%$ were instructors or lecturers, and $15 \%$ were assistant professors. They may not be in a position to mentor other colleagues, although they might have online teaching expertise.

\section{Advise Learners on Their Professional Development-Advisor}

Similarly, advising learners on professional development was rated low as some online instructors may not serve as advisors to their students and may only focus on academic aspects of the course. With $19 \%$ of the respondents in this study being adjunct instructors, they may not be as involved in advising learners or have an opportunity for advising learners outside the course.

\section{Host Synchronous Sessions if Applicable-Facilitator}

Hosting synchronous sessions was rated at 3.66, which is a rating of frequency between "sometimes" and "often." Online programs in the US are mainly asynchronous in delivery (Legon et al., 2020), which was reflected in this survey where $46 \%$ of instructors taught asynchronously online and $12 \%$ entirely synchronously online. It is thus not surprising that faculty members report hosting synchronous sessions, but not "always." It is a good practice to blend asynchronous and synchronous delivery methods in online teaching (Martin et al., 2020b). Resolving Potential Conflicts Among Learners-Manager

This is another optional competency that might be performed by instructors when this problem arises and hence may be rated closer to "often" but not "always." However, it is important for instructors to have the knowledge and skills to be able to resolve potential conflicts among online learners.

\section{Advise Learners on Academic Development-Manager}

There is always room for online instructors to advise students on their academic development as part of the course. Academic development includes factors that affect students' academic, personal, and social development. This was rated at $\mathrm{M}=3.88$ between "sometimes" and "often." In some cases, this is considered as the role of the academic advisor, but online instructors can also play a role in advising learners on academic development.

\section{Ensure Accessibility and ADA compliance-Designer and Developer}


Accessibility and ADA compliance are usually performed as a reactive action when a student with a special need is enrolled in the course. It could also reflect the academic discipline of the instructor and how many students with special needs the program and their institution enroll. Instead, it is important for instructors to also include accessibility and ADA compliance when online courses are designed. Guilbaud (2019) found that instructors rated their knowledge of accessibility and standards low and demonstrated a need for professional development.

\section{Connect Students with Institutional Support Services-Manager}

Similarly, it is important for online instructors to provide information that connects students with institutional support services so that students have a variety of supports for issues that may arise. Instructors do not have to try and solve all the student issues, especially when institutional support is available. Some of the support services could include Library Services, Technical Support, Writing Resource Center, Disability Services office, University Career Center, University Center for Academic Excellence, Counseling Center, and Scholarship Office. Develop Digital Learning Materials-Designer and Developer

Finally, though rated very close to 4.0, developing digital learning materials was rated at 3.98. While instructors who re-use a course that is provided to them may not be developing digital learning materials, they can create digital learning material for course orientations and demonstrations as needed. If they are responsible for the design and facilitation of the course, digital learning materials make learning engaging compared to just text-based resources or integrating existing resources. It is helpful to have instructor-generated learning material which increases instructor presence.

\section{Connections Between Research and Practice}

In general, participants gave highest ratings to competencies related to subject matter and technology expertise; course design, development, facilitation, management, and assessment; and being a lifelong learner. Of these, the need to be a lifelong learner by, for instance, integrating best practices from research into online teaching and staying current with research and theories in the field, are often recommended but not always practiced by online instructors due to lack of time or professional development. The high ratings on these items indicate that connections between research and practice are perceived by the instructors in this survey as essential for their success. The results also highlight the need to help online instructors learn more about research and best practices and go beyond focusing on the more critical tasks important to the success of an online course, notwithstanding the importance of those tasks for student learning.

\section{Online Instructor Competencies Ratings Differ Based on the Requirement for Training}

Online instructors who participated in training to teach online rated the competencies higher than those who did not. While some higher education institutions require faculty to complete training to teach online, others do not. In this study, $37 \%$ of the respondents were required to complete training, $52 \%$ were not required, and $11 \%$ were not sure if they had to complete a required training. Vang et al. (2020) found that in the community college setting, $90 \%$ of instructors were required to participate in training before teaching online. The finding from this study shows that when institutions require training, online instructors rate the competencies higher than those who are not required.

\section{Online Instructor Competencies Ratings Differ Based on Their Collaboration with an Instructional Designer}

Online instructors who collaborated with an instructional designer rated the competencies higher than those who did not. About $63 \%$ of respondents reported that they collaborated with an 
instructional designer, while $33 \%$ did not, and about $3 \%$ were not sure. This finding demonstrates the importance of collaboration with an instructional designer. Halupa (2019) discusses the importance of articulating roles in collaborative processes when instructional designer and instructor work together as design expert and subject matter expert. Brigance (2011) discusses the importance of instructional designers taking the lead in online course design. The findings of this study show the importance of collaboration with an instructional designer, which can result in increased online instructor competencies.

\section{Limitations}

This survey-based study included some methodological limitations. The sample size was small as only 141 valid responses were received. In survey-based research, there is a response bias due to the self-reported nature of the data. The instructors who chose to respond to the questions might be different from those who did not. Also, the competency and roles included in this survey may not be an exhaustive list of all possible online instructor competencies and roles. While instructor competencies were examined based on the instructors training and collaboration with the instructional designer, other variables could also be examined.

\section{Implications and Future Research}

Research on online education and best practices in online teaching has provided insight into best practices, roles, and competencies in online teaching. However, as online teaching is more widely adopted and digital technologies evolve and provide new avenues for online interactions, these online instructor competencies should be continuously revisited, redefined or refined, and adopted for online learner success. The findings of this study, built on prior research, have implications for online instructors, administrators, faculty development professionals, and students. Online instructors might benefit from the various competencies that they can perform, and by comparing their competencies against the most rated competencies and least rated competencies by online instructors in this survey. The findings can inform administrators on areas of support they can provide for online instructors at their institutions, and the competencies that might be needed by faculty appointed to teach online. Faculty development professionals can identify the areas in which they can provide support for online instructors, the competencies that instructors require and whether applicable to their contexts, and adapt these competencies based on their contexts. Some competencies listed in this survey might be relevant for certain disciplines or course levels, which is an area for future exploration. Finally, online students will benefit from this study if the online instructors are able to perform a variety of these competencies.

This study did not include an item asking online instructors whether they had also designed the online courses that they taught. It would be useful to ask such a question in a future study, to distinguish between the ratings for those who design their own courses and those who do not, and to determine whether this influences how the course designer and developer roles are rated. This instrument can also be administered in different types of 2-year or 4-year institutions, as well as globally, to identify variations in online instructor roles and competencies. Administrators can also be surveyed and interviewed to study online instructor competencies. Future research studies can also support the validation of this survey which can then be used by online instructors globally.

\section{Declarations}

The author(s) declared no potential conflicts of interest with respect to the research, authorship, and/or publication of this article. 
The author(s) received approval from the ethics review board of the University of North Carolina-Charlotte for this study.

The author(s) received no financial support for the research, authorship, and/or publication of this article. 


\section{References}

Álvarez, I., Guasch, T., \& Espasa, A. (2009). University teacher roles and competencies in online learning environments: a theoretical analysis of teaching and learning practices. European Journal of Teacher Education, 32(3), 321-336.

Aydin, C. (2005). Turkish mentors' perception of roles, competencies and resources for online teaching. Turkish Online Journal of Distance Education, 6(3). https://dergipark.org.tr/en/pub/tojde/issue/16929/176725

Baran, E., Correia, A-P., \& Thompson, A. (2011) Transforming online teaching practice: Critical analysis of the literature on the roles and competencies of online teachers. Distance Education, 32:3, 421-439, https://doi.org/10.1080/01587919.2011.610293

Barber, W., \& King, S. (2016). Teacher-student perspectives of invisible pedagogy: New directions in online problem-based learning environments. The Electronic Journal of e-Learning Volume, 14(4), 235-243.

Bawane, J., \& Spector, J. (2009). Prioritization of online instructor roles: Implications for competency-based teacher education programs. Distance Education, 30(3), 383-397. https://doi.org/10.1080/01587910903236536

Beck, D., \& Ferdig, R. E. (2008). Evolving roles of online and face-to-face instructors in a lecture/lab hybrid course. TOJET: The Turkish Online Journal of Educational Technology, 7(1).

Bennett, S., \& Lockyer, L. (2004). Becoming an online teacher: Adapting to a changed environment for teaching and learning in higher education. Educational Media International, 41(3), 231-248. doi: 10.1080/09523980410001680842

Berge, Z. (2009). Changing instructor's roles in virtual worlds. Quarterly Review of Distance Education, 9(4), 407-415.

Berge, Z. (1995). The role of the online instructor/facilitator. Educational Technology, 35(1),2230 .

Berry, S. (2017). Building community in online doctoral classrooms: instructor practices that support community. Online Learning 21(2). doi: 10.24059/olj.v21i2.875

Brigance, S. K. (2011). Leadership in online learning in higher education: Why instructional designers for online learning should lead the way. Performance Improvement, 50(10), 43-48.

Borup, J. \& Evmenova, A.S. (2019). The effectiveness of professional development in overcoming obstacles to effective online instruction in a college of education. Online Learning, 23(2), 1-20.

Caplan, D., \& Graham, R. (2004). The development of online courses. Theory and Practice of Online Learning, 2(10), 243-264. 
Chang, C., Shen, H. Y., \& Liu, E. Z. F. (2014). University faculty's perspectives on the roles of e-instructors and their online instruction practice. International Review of Research in Open and Distributed Learning, 15(3), 72-92.

Chao, I. T., Saj, T., \& Hamilton, D. (2010). Using collaborative course development to achieve online course quality standards. International Review of Research in Open and Distributed Learning, 11(3), 106-126.

Cluskey Jr, G. R., Ehlen, C. R., \& Raiborn, M. H. (2011). Thwarting online exam cheating without proctor supervision. Journal of Academic and Business Ethics, 4(1), 1-7.

Conrad, D. (2004). University instructors' reflections on their first online teaching experiences. Journal of Asynchronous Learning Networks, 8(2), 31-44.

Coppola, N., Hiltz, S., \& Rotter, N. (2002). Becoming a virtual professor: Pedagogical roles and asynchronous learning networks. Journal of Management Information Systems, 18(4), 169189.Dempsey, R. (1992). Teachers as leaders: Towards a conceptual framework. Teaching Education, 5(1), 113-122. https://doi.org/10.1080/1047621920050114

Dennen, V. P. (2011). Facilitator presence and identity in online discourse: Use of positioning theory as an analytic framework. Instructional Science, 39(4), 527-541.

Dennis, B., Watland, P., Pirotte, S., \& Verday, N. (2004). Role and competencies of the etutor. In Proceedings of the Networked Learning Conference. (pp. 150-157)

Dietz-Uhler, B., Fisher, A., \& Han, A. (2007). Designing online courses to promote student retention. Journal of Educational Technology Systems, 36(1), 105-112.

Dixson, M., Kuhlhorst, M., \& Reiff, A. (2006). Creating effective online discussions: Optimal instructor and student roles. Journal of Asynchronous Learning Networks, 10(4), 15-28.

Egan, T. M., \& Akdere, M. (2005). Clarifying Distance Education Roles and Competencies: Exploring Similarities and Differences Between Professional and Student-Practitioner Perspectives. American Journal of Distance Education, 19(2), 87-103.

Gibbons, H. S., \& Wentworth, G. P. (2001). Andrological and pedagogical training differences for online instructors. Online Journal of Distance Learning Administration, 4(3).

Goodyear P., Salmon, G., Spector, J.M., Steeples, C. \& Tickner, S. (2001). Competences for online teaching: A special report. Educational Technology, Research and Development, 49(1), 65

Guilbaud, T. C. (2019). Faculty Perception of Knowledge and Practice in Designing and Implementing Accessible Online Courses (Doctoral dissertation, The University of North Carolina at Charlotte). 
Halupa, C. (2019). Differentiation of roles: Instructional designers and faculty in the creation of online courses. International Journal of Higher Education, 8(1), 55-68.

Hung, M. L., \& Chou, C. (2015). Students' perceptions of instructors' roles in blended and online learning environments: A comparative study. Computers \& Education, 81, 315-325.

Johnson, W. B. (2007). Transformational supervision: When supervisors mentor. Professional Psychology: Research and Practice, 38(3), 259.

Khan, A., Egbue, O., Palkie, B., \& Madden, J. (2017). Active learning: Engaging students to maximize learning in an online course. Electronic Journal of E-Learning, 15(2), 107-115.

Klein, J. D., Spector, J. M., Grabowski, B. L., \& de la Teja, I. (2004). Instructor competencies: Standards for face to face, online, and blended settings. IAP.

Kline, R. B. (2016). Principles and practice of structural equation modeling (4th ed.). New York, NY: The Guilford Press.

Lee, D. Y. (2011). Korean and foreign students' perceptions of the teacher's role in a multicultural online learning environment in Korea. Educational Technology Research and Development, 59(6), 913-935.

Legon, R., Garrett, R. \& Fredericksen, E.E. (2020). The changing landscape of online education (CHLOE): Navigating the Mainstream. Quality Matters and Eduventures.

Little, R. J. A. (1988). A test of missing completely at random for multivariate data with_missing values. Journal of the American Statistical Association, 83(404), 1198-1202.

Liu, X., Bonk, C. J., Magjuka, R. J., Lee, S. H., \& Su, B. (2005). Exploring four dimensions of online instructor roles: A program level case study. Journal of Asynchronous Learning Networks, 9(4), 29-48.

Maor, D. (2003). The teacher's role in developing interaction and reflection in an online learning community. Educational Media International, 40(1-2), 127-

138. https://doi.org/10.1080/0952398032000092170

Martin, F., Wang, C., \& Sadaf, A. (2018). Student perception of helpfulness of facilitation strategies that enhance instructor presence, connectedness, engagement and learning in online courses. The Internet and Higher Education, 37, 52-65.

Martin, F., Budhrani, K., Kumar, S., Ritzhaupt, A. (2019a). Award-winning faculty online teaching practices: Roles and competencies. Online Learning Journal, 23(1), 184-205. 
Martin, F., Ritzhaupt, A., Kumar, S., \& Budhrani, K. (2019b). Award-winning faculty online teaching practices: Course design, assessment and evaluation, and Facilitation. The Internet and Higher Education, 42, 34-43.

Martin, F., Budhrani, K., \& Wang, C. (2019c)._ Examining faculty perception of their readiness to teach online, Online Learning Journal, 23(3), 97-119.

Martin, F., Polly, D., \& Ritzhaupt, A. (2020). Bichronous Online Learning: Blending Asynchronous and Synchronous Online Learning, Educause Review. https://er.educause.edu/articles/2020/9/bichronous-online-learning-blending-asynchronous-andsynchronous-online-learning

McGee, P., Windes, D., \& Torres, M. (2017). Experienced online instructors: beliefs and preferred supports regarding online teaching. Journal of Computing in Higher Education, 29, 331-352. https://doi.org/10.1007/s12528-017-9140-6

Milone, A. S., Cortese, A. M., Balestrieri, R. L., \& Pittenger, A. L. (2017). The impact of proctored online exams on the educational experience. Currents in Pharmacy Teaching and Learning, 9(1), 108-114.

Mohr, S., \& Shelton, K. (2017). Best practices framework for online faculty professional development: A Delphi study. Online Learning, 21(4), 123-140.

Moskal, P., Thompson, K., \& Futch, L. (2015). Enrollment, engagement, and satisfaction in the BlendKit faculty development open, online course. Online Learning, 19(4), 1-12.

Muñoz Carril, P. C., González Sanmamed, M., \& Hernández Sellés, N. (2013). Pedagogical roles and competencies of university teachers practicing in the e-learning environment. International Review of Research in Open and Distributed Learning, 14(3), 462-487.

Nunnally, J., \& Berstein, I. (1995). Psychometric theory. McGraw-Hill.

Peters, M.E., Nestadt, P., \& McHugh, P.R. (2017). Role Induction, John Hopkins Psychiatry Guide.

https://www.hopkinsguides.com/hopkins/view/Johns_Hopkins_Psychiatry_Guide/787161/all/Rol e_Induction\#

Quality Matters (2020). QM Rubrics and Standards. https://www.qualitymatters.org/qaresources/rubric-standards

Richardson, J. C., Ashby, I., Alshammari, A. N., Cheng, Z., Johnson, B. S., Krause, T. S., ... \& Wang, H. (2019). Faculty and instructional designers on building successful collaborative relationships. Educational Technology Research and Development, 67(4), 855-880.

Richey, R.C., Fields, D.C., Foxon, M. (2001). Instructional design competencies: The standards, third edition. ERIC Clearinghouse on Information \& Technology. 
Roehm, S., \& Bonnel, W. (2009). Engaging students for learning with online discussions. Teaching and Learning in Nursing, 4(1), 6-9.

Ryan, M., Carlton, K. H., \& Ali, N. S. (2004). Reflections on the role of faculty in distance learning and changing pedagogies. Nursing Education Perspectives, 25(2), 73-80.

Seaman, J. E., Allen, I. E., \& Seaman, J. (2018). Grade Increase: Tracking Distance Education in the United States. Babson Survey Research Group.

Spector, J. M., \& De la Teja, I. (2001). Competencies for Online Teaching. ERIC Digest.

Thach, E. C., \& Murphy, K. L. (1995). Competencies for distance education professionals. Educational Technology Research and Development, 43(1), 57-79.

Vaill, A. L., \& Testori, P. A. (2012). Orientation, mentoring and ongoing support: A three-tiered approach to online faculty development. Journal of Asynchronous Learning Networks, 16(2), 111-119.

Varvel, V. (2007). Master online teacher competencies. Online Journal of Distance Learning Administration, 10(1). Retrieved from http://www2.westga.edu/ distance/ojdla/

Vang, K., Martin, F., \& Wang, C. (2020). Examining community college faculty perceptions of their preparedness to teach online. Journal of Applied Research in the Community College, 27(1), 45-63.

Wiesenberg, F., \& Stacey, E. (2008). Teaching philosophy: Moving from face-to-face to online classrooms. Canadian Journal of University Continuing Education, 34(1), 63-69.

Williams, P. (2003). Roles and competencies for distance education programs in higher education institutions. American Journal of Distance Education, 17(1), 45-57. https://doi.org/10.1207/S15389286AJDE1701_4

Yuksel, I. (2009). Instructor competencies for online courses. Procedia-Social and Behavioral Sciences, 1(1), 1726-1729. 


\section{Appendix A \\ Online Instructor Roles and Competencies}

\section{Instructions}

Please indicate the frequency with which you perform the following roles in your online courses.

[Scale: 1=Never, 2=Rarely, 3=Sometimes, 4=Often, 5=Always]

\section{Subject Matter Expert}

- Demonstrate content expertise

- Stay current with research and theories in the field

- Contribute relevant content to course outcomes

- Collaborate with instructional designers to develop the course

- Ensure that the course content is accurate

- Other:

\section{Course Designer \& Developer}

- Establish learning objectives

- Develop learning activities

- Include existing instructional resources (texts, OERs, videos)

- Develop digital learning materials

- Ensure alignment between objectives, content and, assessment

- Develop a course on the Learning Management System

- Provide consistent course structure

- Design intuitive course navigation

- Consider culturally inclusive content

- Ensure accessibility and ADA-compliance

- Other:

\section{Course Facilitator}

- Create a welcome message (announcement, video)

- Check in with students frequently

- Help students develop self-regulated learning skills (time management)

- Host synchronous sessions if applicable

- Hold online office hours

- Facilitate online discussions

- Use active learning strategies to engage learners

- Provide timely, and substantive feedback

- Foster interaction among learners

- Interact in a culturally sensitive manner

- Offer multiple perspectives

- Encourage student reflection

- Creating a sense of community amongst students from the same course

- Other: 


\section{Course Manager}

- Monitor learner participation

- Provide clear instructions to learners

- Be responsive to individual student needs

- Enforce course and institutional policies

- Resolve potential conflicts among learners

- Connect students with institutional support services

- Other:

\section{Advisor/Mentor}

- Advise learners on their academic development.

- Advise learners on their professional development.

- Motivate the students to succeed.

- Guide students to be self-directed and responsible for their course work

- Guide students to access resources when needed

- Mentor other colleagues who also teach online

- Other:

\section{Assessor/Evaluator}

- Use a variety of assessments (quizzes, projects)

- Align assessment to objectives and activities

- Establish clear grading criteria for assessments

- Assess students' work

- Monitor individual student and group progress

- Proctor online tests if applicable

- Continually improve the course

- Other:

\section{Technology Expert}

- Ensure that students are comfortable in the learning environment

- Orient the students to the online course

- Use appropriate technology to support learning

- Provide students with resources for technical help and support

- Other:

\section{Lifelong Learner}

- Integrate best practices from research into online teaching

- Engage in professional development on online learning

- Share and learn from peers about online teaching practices

- Use data from the online course for continuous improvement

- Keep pace with the advances in educational technologies

- Other:

\section{Open-Ended Questions}

Have you ever taken on a role in an online course other than the ones listed? 


\section{Demographic Information}

Instructions: Please select one answer for each of the following questions.

1. I identify my gender as

- Male (1)

- Female (2)

- Transgender (3)

- Other (4)

- Do not wish to respond (5)

2. My faculty rank is

- Adjunct Instructor (1)

- Instructor or Lecturer (2)

- Assistant Professor (3)

- Associate Professor (4)

- Professor (5)

- Other: (6)

3. I primarily teach in the following learning environment

- Blended or Hybrid (1)

- Online asynchronously (2)

- Online synchronously (3)

- Other (4)

4. I primarily teach

- Undergraduate courses (1)

- Graduate courses (2)

- Other (3)

5. I currently teach at a

- 4-year institution

- 2-year institution

- K-12 school

- Other

6. Years of Online Teaching

- 1-5

- 6-10

- 11-15

- More than 15

7. Academic Discipline

- Arts

- Sciences 
- Business

- Computer Science

- Education

- Engineering

- Health Sciences

- Law

- Medicine

- Other:

8. Have you worked with instructional designers at your institution to develop online courses?

- $\quad$ Yes (1)

- No (2)

- $\quad$ Not sure (3)

9. Does your institution require you to attend training on online teaching?

- Yes (1)

- No (2)

- $\quad$ Not sure (3)

10. In terms of online teaching expertise, I consider myself at the stage of

- Novice (1)

- Advanced beginner (2)

- Intermediate (3)

- Proficient (4)

- $\quad$ Expert (5)

11. How many online courses have you taught?

- $1-5$

- 6-10

- 11-15

- More than 15

Thank you for taking the time to complete this questionnaire. We greatly appreciate your assistance! 